\title{
Characterization of Brazilians Students with Dyslexia in Handwriting Proficiency Screening Questionnaire and Handwriting Scale
}

\section{Giseli Donadon Germano}

São Paulo State University “Júlio de

Mesquita Filho", UNESP,

São Paulo, Brazil

\author{
Catia Giaconi \\ University of Macerata, \\ Macerata, Itália
}

\author{
Simone Aparecida Capellini \\ São Paulo State University "Júlio de \\ Mesquita Filho", UNESP, São Paulo, \\ Brazil
}

\begin{abstract}
Despite technological progress, handwriting still constitutes an important activity among school aged students and is required for during $30 \%-60 \%$ of the school day. The aim of this study was to characterize Brazilians students with developmental dyslexia in handwriting proficiency screening questionnaire and handwriting scale: A total of 51 students with developmental dyslexia, from both genders, from 3rd to 5th grade of Elementary School. As procedure, all students' teachers received and responded the handwriting proficiency screening questionnaire (HPSQ), translated to Brazilian Portuguese Language which is scored on a five Likert scale ranging from 0 - "Never" to 4-"Always", and a final score is summed. The questionnaire's reliability and validity have been established and a sum of 14 was determined as the cut of score for handwriting deficiency. The Dysgraphia scale ranged from 0 to 17 points, being considered as having a dysgraphia pattern the student that obtained a grade equal to or greater than 8.5 points. Regarding HPSQ, 26 (50.9\%) of dyslexic's students scored above 14 points, being characterized to have a handwriting deficiency. Among the questions, most of the answers given by teachers was referring to "rarely", which suggest that they don't have perception of the handwriting difficulties of these students. Regarding the handwriting scale, 43 students (84.3\%) met criteria for dysgraphia. Also, a statistical analysis was carried out, indicating that there was statistical difference between each question with the classification of dysgraphia. These results point to the necessity of orientation to teachers on the quality of writing students with dyslexia.
\end{abstract}

Keywords: dyslexia, assessment, handwriting, education

\section{Introduction}

Developmental dyslexia is a specific disorder of learning, of neurological origin, characterized by difficulty with the correct fluency in reading and difficulty in decoding and spelling skills, resulting in a deficit in the phonological component of language (Lyon, Shaywitz, \& Shaywitz, 2003).

\footnotetext{
*Acknowledgements: National Council for Scientific and Technological Development $-\mathrm{CNPq}$ for financial support (Process $\mathrm{n}^{\mathrm{o}}$ 475711/2009-2 and Process $n^{\circ}$ 455208/2014-0).

Giseli Donadon Germano, Investigation Learning Disabilities Laboratory, Speech and Hearing Sciences Department, São Paulo State University "Júlio de Mesquita Filho", UNESP.

Catia Giaconi, Department of Education, Cultural Heritage and Tourism at the University of Macerata.

Simone Aparecida Capellini, Investigation Learning Disabilities Laboratory at the Speech and Hearing Sciences Department, São Paulo State University “Júlio de Mesquita Filho", UNESP.
} 
Tseng and Chow (2000) reported that students with dyslexia, the handwriting speed might bealtered by failures of visual perception or failures in the underlying cognitive skills. Also, studies about dyslexia, referred experimental evidence that students with dyslexia often suffer from fine and gross motor difficulties, like motor coordination, poor balance and clumsiness (Capellini, Coppede, \& Valle, 2010; Fusco, Germano, \& Capellini, 2015; Nicolson \& Fawcett, 1990; Pagliarini et al., 2015).

Regarding motor perceptual-vision skills, Fusco et al. (2015) conducted a study to determine the effectiveness of an intervention program with perceptual and visomotor skills to students with dyslexia and control group. The program consisted of exercises for eye-hand coordination, visual discrimination, visual memory, visual-spatial relationship, the constancy of form, the sequential memory, and visual figure-ground and visual closure. As a result, the program has shown positive effects because it improved visual perception skills and handwriting quality in dyslexia students and also in students with good academic performance (control group).

Handwriting requires fine graded manipulation of pencils to produce letter forms, in a fluent and ballistic manner, with a specific orientation and size, in a specific serial order, and in specific positions on a writing surface (van Galen, 1993). Further, according to Sovik and Arntzen (1991), fluent writing is produced by an integrated pattern of coordinated movements subject to visual monitoring and sensorimotor feedback (Tseng \& Chow, 2000).

The authors also indicated that much could also be inferred from the various ways in which handwriters do not achieve functional competence. Handwriting can be deficient either in terms of legibility or in terms of speed. Common handwriting problems such as incorrect letter formation, poor alignment, reversals, uneven size of letters, irregular spacing between letters and words, and slow motor speed do not necessarily arise from identical underlying mechanisms. Most studies to date, however, have focused primarily on the relationship between illegibility and various visual-perception skills, fine motor skills, and visual-motor integration.

One of the manifestations arising from visuomotor perception change is the dysgraphia, which according with DSM-V (American Psychiatric Association (APA), 2013) is described as a neurodevelopmental disorders, such as a specific learning disorder of written expression and can be a predictor or co-occur with other learning problems. The dysgraphia can be further classified into two types: the perceptual and motor dysgraphia. The perceptual dysgraphia is described, as a difficulty of the student that cannot make the relationship between the symbolic system and spellings that represent sounds, words and phrases. The motor dysgraphia is described as the students can speak and read, but has difficulties in fine motor skills to write letters, words and numbers, in other words, they are able to see the graphic picture, but they cannot make the moves to write (Alstad et al., 2015).

Although several studies have been conducted internationally, studies with the Brazilian population are rare. The aim of this study was to characterize Brazilians students with developmental dyslexia in handwriting proficiency screening questionnaire and handwriting scale.

\section{Method}

This study was approved by Ethics Committee of the Faculty of Philosophy and Sciences, São Paulo State University “Júlio de Mesquita Filho", UNESP—Marília—São Paulo, Brazil, under protocol number 0182/2011.

A total of 51 students with developmental dyslexia, from both genders, from 3rd to 5 th grade of Elementary School from the Investigation Learning Disabilities Laboratory at the Speech and Hearing Sciences 
Department—São Paulo State University "Júlio de Mesquita Filho" —UNESP—Marília—São Paulo—Brazil.

As procedure, all students' teachers received and responded the handwriting proficiency screening questionnaire (HPSQ, Rosenblum, 2008) translated to Brazilian Portuguese Language and the students were submitted to the handwriting scale (Lorenzini, 1993).

\section{Handwriting Proficiency Screening Questionnaire (HPSQ, Rosenblum, 2008)}

The HPSQ is a 10-item questionnaire that was developed to identify school-aged students with handwriting difficulties. The 10 items cover the most important indicators of handwriting deficiencies in the following three domains: (1) legibility (items 1, 2, 10); (2) time performance (items 3, 4, 9); and (3) physical and emotional well-being (items 5-8) (Cornhill \& Case-Smith, 1996; Rubin \& Henderson, 1982). The items are worded to enable the teachers to respond while performing their observations of students as they are writing in the classroom. For example, "does the child often erase while writing?"

The items are scored on a five-point Likert scale, ranging from 0 ("Never") to 4 ("Always"), with higher scores indicating poorer performance. The final score is computed by summing the scores of all the 10 test items. The questionnaire's content validity, internal consistency, inter-rater and test-retest reliability have been established (see Rosenblum, 2008 for more details). Based on the analysis of the HPSQ scores of 230 school-aged students (between 7 and 14 years old) a cut-off score of 14 (mean + SD) was established for the identification of handwriting deficiency (Rosenblum, 2008).

\section{Scale of Dysgraphia (Lorenzini, 1993)}

The procedure is performed individually with duration of up to five minutes. The student is asked to write under dictation of a message on a blank sheet of paper (no lines or edges). The use of rubber not allowed.

This procedure aimed to allow the analyzes of the following writing aspects: flowing lines, progeny and/or ascending lines, irregular space between words, retouched letters, curvatures and angles of the arches of the letters "m", "n", "u" and "v", junction points, collisions and adherences, sudden movements, irregular in size and bad forms. The dysgraphia scale ranged from 0 to 17 points, being considered as having a dysgraphia pattern the student that obtained a grade equal to or greater than 8.5 points.

\section{Results and Discussion}

All the results were analyzed statistically. First, at Table 1, a descriptive analysis was carried out to characterize the studied population for the questionnaire (HPSQ), scored on a five-point Likert scale, ranging from 0 ("Never") to 4 (“Always").

Table 1

Distribution of Frequency of Each Question (Q1 to Q10) of HPSQ Questionnaire Regarding the Classification (CL)

\begin{tabular}{lcccccccccc}
\hline CL & Q1 & Q2 & Q3 & Q4 & Q5 & Q6 & Q7 & Q8 & Q9 & Q10 \\
\hline 0 & 18 & 20 & 18 & 2 & 25 & 22 & 78 & 49 & 6 & 55 \\
1 & 31 & 37 & 33 & 12 & 35 & 37 & 14 & 33 & 16 & 24 \\
2 & 29 & 29 & 29 & 47 & 27 & 29 & 8 & 18 & 31 & 20 \\
3 & 14 & 8 & 12 & 29 & 10 & 8 & 0 & 0 & 25 & 2 \\
4 & 8 & 6 & 18 & 10 & 2 & 4 & 0 & 0 & 22 & 0 \\
$p$-value & $0.033^{*}$ & $0.001^{*}$ & $0.014^{*}$ & $0.000^{*}$ & $0.001^{*}$ & $0.000^{*}$ & $0.000^{*}$ & $0.023^{*}$ & $0.046^{*}$ & $0.000^{*}$ \\
Total & 100 & 100 & 100 & 100 & 100 & 100 & 100 & 100 & 100 & 100 \\
\hline
\end{tabular}

Notes. Caption: Never (0); Rarely (1); Sometimes (2); Frequently (3); Always (4). Chi-Square Test ( $p<0.05$ ). 
Regarding Table 1, there was significant difference in all questions, regarding the classification of teachers at HPSQ questionnaire. Concerning the indicators of handwriting deficiencies in the following domains of legibility (questions 1, 2, 10), most of the teachers didn't present a real complain about those items. Legibility means how readable a passage written by a person is.

In question 1 (Q1), when asked about the legibility of writing, $49 \%$ of the students were classified as "Never" and "Rarely" against 51\% of "Sometimes", "Frequently" and "Always"; in question 2 (Q2) about if the student has difficulties to read his own writing, $57 \%$ of the students were classified as "Never" and "Rarely"; in question 10 (Q10) about if the student shows not satisfied with your writing, 79\% of the students were classified as "Never" and "Rarely".

Concerning the indicators of handwriting deficiencies in the following domains of (2) performance time (questions 3, 4, 9). The question 3 (Q3) referred about having enough time to copy the blackboard, $51 \%$ of the students were classified as "Never" and "Rarely" against 59\% of "Sometimes", "Frequently" and "Always". The question $4(\mathrm{Q} 4)$ referred about making mistakes while writing, $86 \%$ of the students were classified as "Sometimes", "Frequently" and "Always". The question 9 (Q9) referred about the need of looking at the board or in the book while copying making mistakes while writing, 79\% classified as "Never" and "Rarely".

Concerning the indicators of handwriting deficiencies in the following domains of physical and emotional well being (questions Q5, Q6, Q7 and Q8), most of the students were classified as "Never" and "Rarely" (60\%, $59 \%, 92 \%$ and $82 \%$, respectively).

These results allow us to draw three different suppositions: (1) Teachers of dyslexic students don't have any complains about the legibility, time or physical and emotional well-being; (2) Dyslexics' students don't recognize theirs handwritings difficulties or perception about their movements or its quality; and (3) Most important, perhaps the teachers don't have enough knowledge about handwriting skills. This last supposition is extremely important, if we consider that handwriting is used in most of the time in class activities. The only aspect that was pointed by the teachers was about the "making mistakes in writing", however, they showed preoccupation about the orthography aspect and not about the format aspects.

Handwriting is a major occupation for students. The use of paper and a writing instrument is a common and frequent part of every child's school day. For school-aged students, the ability to produce fluent and legible writing is important for expressing, communicating and recording ideas as well as for educational development. Failure of this learning process often leads to poor school performance. Previous literature has found that visual perception skills and visual-motor integration skills are the main crucial factors, or predictors, for predicting handwriting performance, including both legibility and speed (Poon, Li-Tsang, Weiss, \& Rosenblum, 2010).

Tseng and Chow (2000) review the literature and reported that poor coordination in the form of irregular dissociation of members (e.g., exaggerated movement of the wrist and thumb) was inversely correlated with the writing speed. In this respect, write slower students with good academic performance characterized students with dyslexia. These findings suggested that the writing speed might have been altered by failures of visual perception or failures in the underlying cognitive skills.

The visomotor integration requires the conjunction of voluntary attention and the act of programming and reprogramming of the body movements that will perform motor activity. Thus, the effectiveness of speed programming occurs in the way that tactile-perceptual information fit into visual information (Germano, Pinheiro, Okuda, \& Capellini, 2013). 
Based on the analysis of the HPSQ scores, Rosenblum (2008) established a cut-off score of 14 for the identification of handwriting deficiency. Table 2 summarizes these results of the students that would be classified as dysgraphic or non-dysgrafic.

Table 2

Distribution of Number, Frequency and p-Value of the Sum of Each Question (Q1 to Q10) of HPSQ Questionnaire

\begin{tabular}{lccc}
\hline & $N$ & Frequency & $p$-value \\
\hline Non-dysgrafic & 27 & 53 & 0.674 \\
Dysgraphic & 24 & 47 & \\
Total & 51 & 100 & \\
\hline
\end{tabular}

Note. Chi-Square Test $(p<0.05)$.

According Table 2, there wasn't a statistic difference between the classifications of HPSQ questionnaire, suggesting that this procedure is not enough to distinguish or to qualify the handwriting profile of dyslexic's students based only in the response of the teachers.

Concerning the Scale of Dysgraphia (Lorenzini, 1993), it was possible to characterize the dyslexic handwriting, using the criterion of the procedure. Table 3 summarizes these results.

Table 3

Distribution of Number, Frequency and p-Value of the Results of Scale of Dysgraphia

\begin{tabular}{lccc}
\hline & $N$ & Frequency & $p$-value \\
\hline Non-dysgrafic & 8 & 16 & \\
Dysgraphic & 43 & 84 & $0.000^{*}$ \\
Total & 51 & 100 & \\
\hline
\end{tabular}

Note. Chi-Square Test $(p<0.05)$.

Regarding Table 3, it was possible to observe that there was statistic difference between the classifications of the scale of dysgraphia. About this scale, it was able to observe that most of the students $(84 \%)$ met criteria for dysgraphia.

These findings led us to suppose that there's a substantial quantity of students with dyslexia might have problems regarding flowing lines, progeny and/or ascending lines, irregular space between words, retouched letters, curvatures and angles of the arches of the letters " $m$ ", " $n$ ", " $u$ " and "v", junction points, collisions and adherences, sudden movements, irregular in size and bad forms. Unfortunately, this finding wasn't totally perceived by the teachers in the HPSQ questionnaire.

Döhla and Heim (2016) described that developmental dysgraphia is a disorder characterized by difficulties in the acquisition of writing skills, with writing performance below that expected based on students' class level. It is closely related to developmental dyslexia, a disorder in the acquisition of reading skills, and like developmental dysgraphia, despite adequate visual, schooling, and other cognitive abilities. The prevalence for developmental writing disorders is about 7\%-15\% among school-aged students.

Pagliarini et al. (2015) also indicated that students with dysgraphia, who are not proficient in handwriting, produce poor quality script due to variable letter shapes and spacing. More specifically, their handwriting product is characterized by more variability in size, dysfluency, lignment, inadequate spatial organization, longer in-air time, increased pause time per stroke and an increased number of directional changes in velocity. 
Regarding the dyslexia definition, Facoetti et al. (2003) suggest an alteration of phonological and orthographic representation as an indirect consequence of the deficit in spatial attention that, in turn, impairs a dyslexic's student learning to read. Since phonological and orthographic representations are also accessed during writing, this implies that attention has an impact on the acquisition of writing skills as well.

Because the frames of dyslexia and learning disabilities are related to alteration in academic performance, most studies are focused mainly on the description of linguistic and cognitive behaviors related to reading and writing. However, studies indicate the presence of changes in motor skills of this population (Getchell, Pabreja, Neeld, \& Carrio, 2007; Tseng \& Chow, 2000) and visuomotor (Feretti, Mazzotti, \& Brizzolara, 2008; Fusco et al., 2015; Germano, Reilhac, Capellini, \& Valdois, 2014).

Studies have shown that dyslexic population has difficulties in bimanual coordination, manual dexterity and fine motor skills, which could explain the occurrence of dysgraphia in this population (Capellini \& Souza, 2008; Summers, Larkin, \& Dewey, 2008).

Rosenblum, Weiss, and Parush (2004) assessed handwriting of dysgraphic students. They summarize research and describe the problem of dysgraphics having not fully automatized letter production. Therefore, dysgraphics have an increased demand on their memory and attention while writing. Consequently, higher-level cognitive processes are constrained. As a further limitation, these authors describe the fact that students may forget plans held in memory before they are able to write them down on paper because of slow handwriting. This deficit may lead to serious consequences for students' academic process, their emotional well-being and their social function. The authors confirm the characteristics of dysgraphic writing such as consistently lower quality of individual spatial writing features. This includes inconsistent letter size, acute turns in letters, uneven and unsteady writing as well as sudden changes in size and direction of letter writing. Similar findings were described in the Brazilian learning disabilities study developed by Germano et al. (2013) and Fusco et al. (2015).

Finally, the question about the origin of dysgraphia, or whether it results from a perceptual and visual-motor alteration, alteration of fine motor function, linguistic alteration or all of those aspects permeate studies (Capellini, Coppede, \& Vallle, 2010; Gabbard \& Caçola, 2010; Okuda et al., 2011; Rosenblum, Aloni, \& Josman, 2009), therefore, still there is needs a continuum of studies the handwriting profile of students who have as manifestation dysgraphia, and more specifically studies with students who have a diagnosis of dyslexia to identify the origin of the dysgraphic handwriting, to determine if this is due to fine motor function déficit, to visual perceptual alteration or if this occur because there is the both alteration.

\section{Conclusions}

Regarding HPSQ, 26 (50.9\%) of dyslexic's students scored above 14 points, being characterized to have a handwriting deficiency. Among the questions, most of the answers given by teachers were referring to "rarely", which suggest that they don't have perception of the handwriting difficulties of these students.

Regarding the handwriting scale, 43 students $(84.3 \%)$ met criteria for dysgraphia. Also, a statistical analysis was carried out, indicating that there was statistical difference between each question with the classification of dysgraphia. These results point to the necessity of orientation to teachers on the quality of handwriting students with dyslexia. 


\section{References}

Alstad, Z., Sanders, E., Abbott, R. D., Barnett, A. L., Henderson, S. E., Connelly, V., \& Berninger, V. W. (2015). Modes of alphabet letter production during middle childhood and adolescence: Interrelationships with each other and other writing skills. Journal of Writing Research, 6(3), 199-231.

American Psychiatric Association. DSM-V. (2013). Diagnostic and statistical manual of mental disorders (5th ed.). Arlington, VA: American Psychiatric Publishing.

Capellini, S., Coppede, A. C., \& Valle, T. R. (2010). Fine motor function of school-aged children with dyslexia, learning disability and learning difficulties. Pró-Fono Revista de Atualização Científica, 23(3), 201-208. Doi:10.1590/S0104-56872010000300008

Capellini, S. A., \& Souza, A. V. (2008). Avaliação da função motora fina, sensorial e perceptiva em escolares com dislexia. In A. L. Sennyey, F. C., Capovilla, \& J. M., Montiel (Eds.), Transtornos da aprendizagem da avaliação à reabilitação. São Paulo: Editora Artes Médicas.

Cornhill, H., \& Case-Smith, J. (1996). Factors that relates to good and poor handwriting. American Journal of Occupational Therapy, 50, 732-739. Doi:10.5014/ajot.50.9.732

Döhla, D., \& Heim, S. (2016). Developmental dyslexia and dysgraphia: What can we learn from the one about the other? Frontiers in Psychology, 6, 2045. Doi:10.3389/fpsyg.2015.02045

Facoetti, A., Lorusso, M. L., Paganoni, P., Cattaneo, C., Galli, R., Umilta, C., et al. (2003). Auditory and visual automatic attention deficits in developmental dyslexia. Cognitive Brain Research, 16, 185-191. Doi:10.1016/s0926-6410(02)00270-7.

Ferretti, G., Mazzotti, S., \& Brizzolara, D. (2008). Visual scanning and reading ability in normal and dyslexic children. Behavioural Neurology, 19(1-2), 87-92. Doi:10.1155/2008/564561.

Fusco, N., Germano, G. D., \& Capellini, S. A. (2015). Efficacy of a perceptual and visual-motor skill intervention program for students with dyslexia. Codas, 27(2), 128-134. Doi:10.1590/2317-1782/20152014013

Gabbard, C., \& Caçola, P. (2010). Los niños con trastorno del desarrollo de la coordinación tienen dificultad on la representación de las acciones. Revista Neurológia, 50, 33-8.

Germano, G. D., Reilhac, C., Capellini, S. A., \& Valdois, S. (2014). The phonological and visual basis of developmental dyslexia in Brazilian Portuguese reading children. Frontiers in Psychology, 5. Doi:10.3389/fpsyg.2014.01169

Germano, G. D., Pinheiro, F. H., Okuda, P. M. M., \& Capellini, S. A. (2013). Visual-motor perception in students with attention deficit with hyperactivity disorder. CoDAS, 25(4), 337-341. Doi:10.1590/S2317-17822013000400007

Getchell, N., Pabreja, P., Neeld, K., \& Carrio, V. (2007). Comparing children with and without dyslexia on the movement assessment battery for children and the test of gross motor development. Perceptual and Motor Skills, 105, $207-214$. Doi:10.2466/pms.105.5.207-214.

Lorenzini, V. L. (1993). Uma escala para detectar a disgra a baseada na escala de Ajuriaguerra (dissertação). São Carlos: Universidade Federal de São Carlos.

Lyon, G. R., Shaywitz, S. E., \& Shaywitz, B. A. (2003). A definition of dyslexia. Annals of Dyslexia, 53(1), 1-14.

Nicolson, R. I., \& Fawcett, A. J. (1990). Automaticity: A new framework for dyslexia research? Cognition, 35, 159-182.

Okuda, P. M. M., Lourencetti, M. D., Santos, L. C. A., Padula, N. A. M. R., \& Capellini, S. A. (2011). Fine motor coordination of students with dyslexia and attention deficit disorder with hiperactivity. Revista CEFAC, 13(5), 876-885. Doi:10.1590/S1516-18462011005000048

Pagliarini, E., Guasti, M. T., Toneatto, C., Granocchio, E., Riva, F., Sarti, D., Molteni, B., \& Stucchi, N. (2015). Dyslexic children fail to comply with the rhythmic constraints of handwriting. Human Movement Science, 42, 161-182. Doi:10.1016/j.humov.2015.04.012.

Poon, K. W., Li-Tsang, C. W. P., Weiss, T. P. L., \& Rosenblum, S. (2010). The effect of a computerized visual perception and visual-motor integration-training program on improving Chinese handwriting of children with handwriting difficulties. Research in Developmental Disabilities, 31, 1552-1560. Doi:10.1016/j.ridd.2010.06.001

Rosenblum, S. (2008). Development, reliability and validity of the handwriting proficiency screening questionnaire (HPSQ). American Journal of Occupational Therapy, 62, 298-307. Doi:10.5014/ajot.62.3.298

Rosenblum, S., Aloni, T., \& Josman, N. (2010). Relationships between handwriting performance and organizational abilities among children with and without dysgraphia: A preliminary study. Research in Developmental Disabilities, 31(2), 502-509. Doi:10.1016/j.ridd.2009.10.016 
Rosenblum, S., Weiss, P. L., \& Parush, S. (2004). Handwriting evaluation for developmental dysgraphia: Process versus product. Reading and Writing, 17, 433-458. Doi:10.1023/b:read.0000044596.91833.55

Rubin, N., \& Henderson, S. E. (1982). Two sides of the same coin: Variation in teaching methods and failure to learn to write. Special Education: Forward Trends, 9, 17-24. Doi:10.1111/j.1467-8578.1982.tb00576.x

Sovik, N., \& Arntzen, O. (1991). A developmental study of the relation between the movement patterns in letter combinations (words) and writing. In J. Wann, A. M. Wing, \& N. Sovik (Eds.), Development of graphic skills: Research perspective and educational implications (pp. 77-89). New York: Academic Press.

Summers, J., Larkin, D., \& Dewey. D. (2008). Activities of daily living in children with developmental coordination disorder: Dressing, personal hygiene, and eating skills. Human Movement Science, 27, 215-229. Doi:10.1016/j.humov.2008.02.002

Tseng, M. H., \& Chow, S. M. K. (2000). Perceptual-motor function of school-age children with slow handwriting speed. American Journal of Occupational Therapy, 54, 83-88. Doi:10.5014/ajot.54.1.83

van Galen, G. P. (1993). Handwriting: A developmental perspective. In A. F. Kalverboer, B. Hopkins, \& R. Geuze (Eds.), Motor development in early and later childhood: Longitudinal approaches (pp. 217-228). New York: Cambridge University. 